\title{
Proceeding Paper \\ Development of a Bioelectronic Tongue Modified with Gold Nanoparticles for Dairy Analysis ${ }^{+}$
}

\author{
Clara Pérez-González ${ }^{1,2}$, Coral Salvo-Comino ${ }^{2,3}$, Fernando Martin-Pedrosa ${ }^{1,2}$, Cristina García-Cabezón 1,2,*(D) \\ and María Luz Rodríguez Méndez 2,3,*iD
}

1 Material Science Departament, University of Valladolid, Escuela de Ingenierías Industriales Paseo del Cauce, 59, 47011 Valladolid, Spain; claraperez.biotecnologia@gmail.com (C.P.-G.); fmp@eii.uva.es (F.M.-P.)

2 Group UVaSens, University of Valladolid, Escuela de Ingenierías Industriales Paseo del Cauce, 59, 47011 Valladolid, Spain; coraldeugena@hotmail.com

3 Inorganic Chemistry Departament, University of Valladolid, Escuela de Ingenierías Industriales Paseo del Cauce, 59, 47011 Valladolid, Spain

* Correspondence: crigar@eii.uva.es (C.G.-C.); mluz@eii.uva.es (M.L.R.M.)

+ Presented at the 1st International Electronic Conference on Chemical Sensors and Analytical Chemistry, 1-15 July 2021; Available online: https://csac2021.sciforum.net/.

check for updates

Citation: Pérez-González, C.;

Salvo-Comino, C.; Martin-Pedrosa, F.; García-Cabezón, C.; Rodríguez Méndez, M.L. Development of a Bioelectronic Tongue Modified with Gold Nanoparticles for Dairy Analysis. Chem. Proc. 2021, 5, 31. https://doi.org/10.3390/CSAC202110553

Academic Editor: Núria Serrano

Published: 1 July 2021

Publisher's Note: MDPI stays neutral with regard to jurisdictional claims in published maps and institutional affiliations.

Copyright: (c) 2021 by the authors. Licensee MDPI, Basel, Switzerland. This article is an open access article distributed under the terms and conditions of the Creative Commons Attribution (CC BY) license (https:// creativecommons.org/licenses/by/ $4.0 /)$.

\begin{abstract}
The objective of this work was to create an all-solid-state potentiometric bioelectronic tongue with an array of polymeric membrane-based sensors, which could then be used in the dairy sector. Membranes were modified with gold nanoparticles, and enzymes were covalently linked to the sensor's surface to create an array of sensors with greater sensitivity. The responses of the sensors modified with gold nanoparticles and covalently associated enzymes, showed higher sensitivities. Moreover, the developed bioelectronic tongue was able to perform the discrimination of milks with different nutritional characteristics by applying principal component analysis. In addition, the results obtained showed that by applying partial least squares analysis, the system could be used as a prediction system for different chemical parameters (such as acidity, proteins, lactose, etc.).
\end{abstract}

Keywords: electronic tongue; biosensor; potentiometric; dairy industry; nanoparticles

\section{Introduction}

The concept of electronic tongues has expanded rapidly during recent years due to their large potential. E-tongues are based on sensor arrays with low selectivity and high cross-selectivity between multiple sensors [1]. Unlike other analytical methods, this type of device allows the acquisition of chemical information from different matrixes by applying suitable multivariate statistical, qualitative or quantitative data processing techniques, thereby targeting issues to overcome drawbacks, such as the requirement to pretreat samples, noise issues, and collinearity between variables [2].

E-tongues can implement a range of transduction principles, electrochemical sensors (potentiometric, amperometric, voltammetric, or impedimetric sensors) being the most common sensors applied in the development of e-tongues. Potentiometric sensors are based on the measurement of the differences in the interface potential created across a selective membrane. The interaction between the electrode and the solution determines this potential, which is related to the physicochemical properties of the solutions under inquiry [3].

The objective of this work was to design an all-solid-state potentiometric bioelectronic tongue (bio-ET) dedicated to the dairy sector, using an array of biosensors based on polymeric membranes operating in parallel. The membranes were modified with gold nanoparticles (AuNPs) to create an array of sensors with greater sensitivity [4]. Moreover, to further improve the sensor's selectivity, enzymes, including galactose oxidase, urease, and lactate dehydrogenase, were covalently attached to the PVC surface. The bio-ET has been applied to the analysis of milk samples with different nutritional contents. 


\section{Materials and Methods}

The electronic tongue was constructed by combining sensors based on polymeric matrices that differ in composition. The polymeric membranes were made of PVC [poly(vinyl chloride)] mixed with an additive (oleyl alcohol), a plasticiser [(bis(1-butylpentyl) adipate, tris(2ethylhexyl)phosphate or 2-nitrophenyl-octylether] and gold nanoparticles creating an array of 27 sensors. Each of the polymeric mixtures were applied on solid conducting silver-epoxy supports. The bio-ET was composed of the sensor array, an $\mathrm{Ag} / \mathrm{AgCl}$ reference electrode, and a data-collecting multiplexer.

The effect of gold nanoparticles and the bioelectronic tongue performance was tested by analysing six standard solutions at concentrations ranging from $1 \times 10^{-3}$ to $1 \times 10^{-1} \mathrm{~mol} / \mathrm{L}$. When applying the multivariate analysis technique, a set of sensors was selected for the construction of a bio-ET that was applied to twelve commercial milk samples. Potentiometric signals obtained from the array of sensors were processed using principal component analysis (PCA). Using partial least squares (PLS), correlations between the responses of the sensors and the chemical parameters were established.

\section{Results}

The results obtained in this research indicate that sensors with a higher percentage of gold nanoparticles in their composition showed higher sensitivities towards compounds found in milk. An example of the sensor behaviour is shown in Figure 1. This behaviour could be due to an increase in the sensitivity of the sensors towards specific ions on the interface of the polymeric membrane when AuNPs are included in the matrix composition.

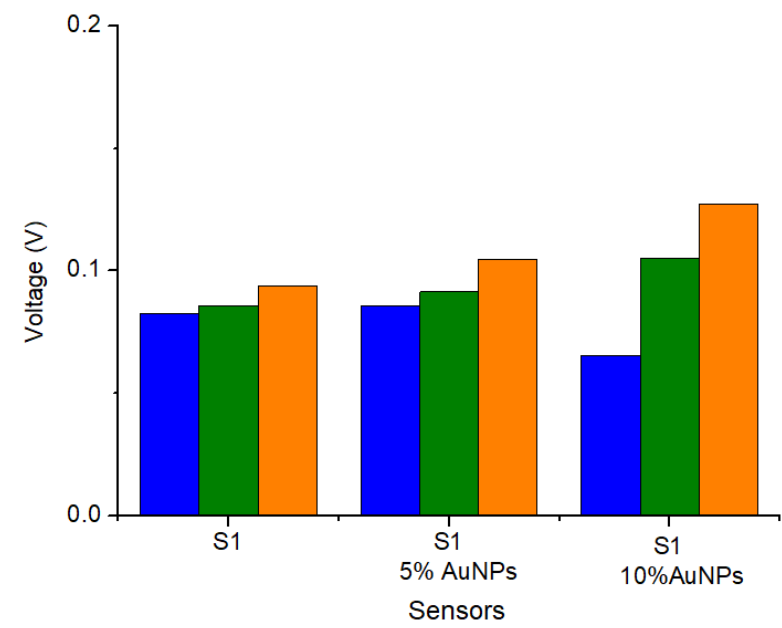

Figure 1. Each sensor's response to glucose at increasing concentrations (blue $=10^{-4} \mathrm{M}$, green $=10^{-3} \mathrm{M}$, and orange $=10^{-2} \mathrm{M}$ ) depending on the percentage of AuNPs applied to the membrane matrix.

Moreover, the sensor that combined gold nanoparticles with enzymes showed a greater ability to differentiate between increasing concentrations of products of interest found in milk, such as urea, lactic acid, galactose, etc., with deviations of voltages up to $65 \mathrm{mV}$ between different samples.

Furthermore, using statistical analysis (PCA), the constructed bioelectronic tongue was able to classify milk with various nutritional features, resulting in four distinct groups that were also sorted according to the fat content of the samples (Figure 2). 


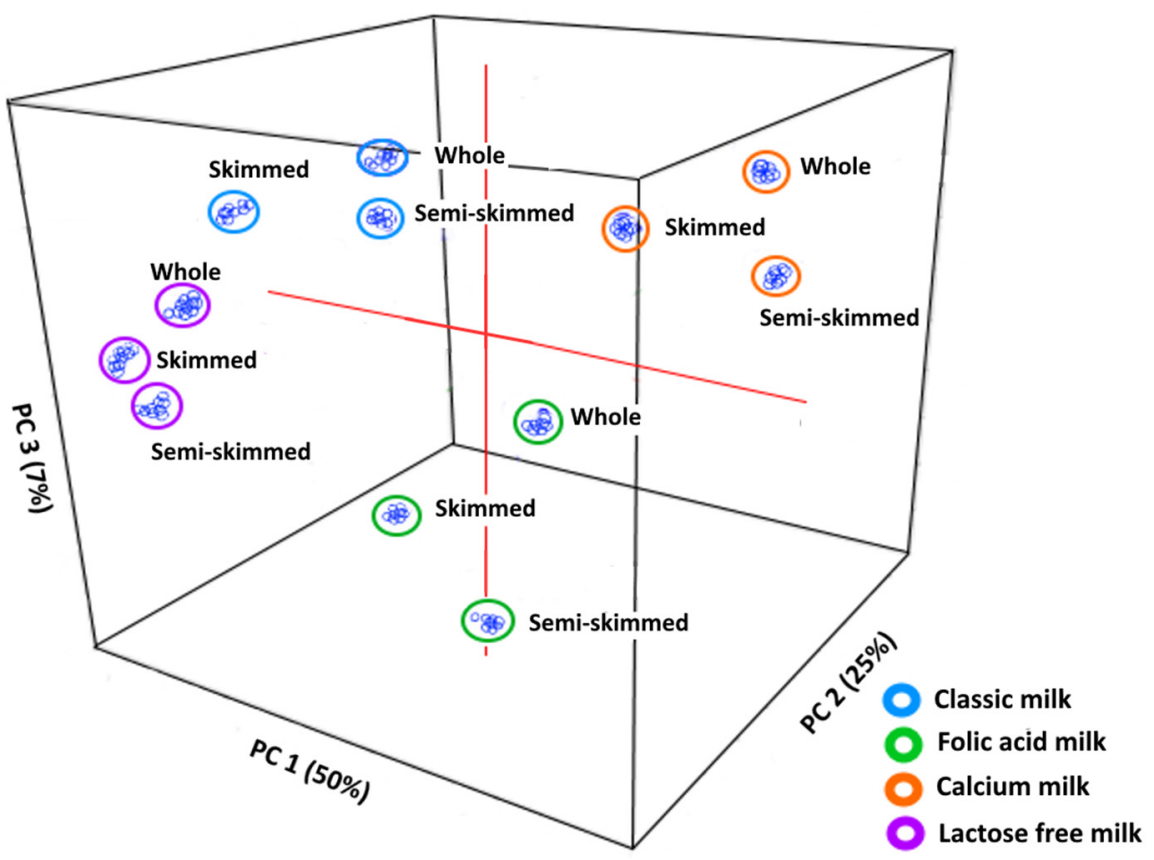

Figure 2. Classification of the milk samples studied according to the score diagram of the principal component analysis.

Additionally, the study's findings revealed that using partial least squares analysis (PLS), with regression coefficients above 0.85 for three variables in the physio-chemical parameters studied, the developed bioelectronic tongue could be used as a prediction system to determine the parameters, such as density, acidity, lactose, or fat content, of future milk samples (Table 1).

Table 1. Correlation parameters resulting from the regression of partial least squares analysis (PLS).

\begin{tabular}{cccccc}
\hline Parameters & $\mathbf{R}_{\mathbf{C}}$ & RMSE $_{\mathbf{C}}$ & R2 $_{\mathbf{P}}$ & RMSE $_{\mathbf{P}}$ & $\begin{array}{c}\text { Latent } \\
\text { Variables }\end{array}$ \\
\hline Acids & 0.8683 & 0.2894 & 0.8483 & 0.2753 & 3 \\
Density & 0.8729 & 0.5172 & 0.8621 & 0.5736 & 3 \\
\%Proteins & 0.8629 & 0.1027 & 0.8432 & 0.1251 & 3 \\
\%Fat & 0.8512 & 0.4723 & 0.8404 & 0.4817 & 3 \\
\%Lactose & 0.8895 & 0.0553 & 0.8813 & 0.0577 & 3 \\
\hline
\end{tabular}

\section{Conclusions}

In this work, a bioelectronic tongue was developed and used to predict the chemical characteristics of milk. Sensors with higher concentrations of gold nanoparticles in their composition showed greater sensitivity towards the compounds of interest in milk (such as lactic acid, galactose, and urea). The system, using nine potentiometric sensors, could be successfully used to discriminate between milks, applying PCA based on their nutritional content. The bio-ET was successfully used to predict the acidity and density, in addition to the protein, lactose, and fat content of the milk, with low errors and high correlation coefficients for three factors. This device could be adapted for its implementation in the dairy industry.

Funding: MICINN-FEDER Plan Nacional (RTI2018-097990-B-100), Consejería de Educación Junta de Castilla y Leon- FEDER VA275P18 and «Infraestructuras Red de Castilla y León (INFRARED)» UVA01.

Institutional Review Board Statement: Not applicable.

Informed Consent Statement: Not applicable. 
Conflicts of Interest: The authors declare no conflict of interest.

\section{References}

1. Ródriguez-Mendez, M.L.; De Saja, J.A.; González-Antón, R. Electronic Noses and Tongues in Wine Industry. Front. Bioeng. Biotechnol. 2016, 4, 81. [CrossRef] [PubMed]

2. Wasilewski, T.; Wojciech, K.; Jacek, G. Bioelectronic Tongue: Current Status and Perspectives. Biosens. Bioelectron. 2020, 150, 111923. [CrossRef] [PubMed]

3. Bakker, E.; Pretsch, E. Potentiometric Sensors for Trace-Level Analysis. Trac Trends Anal. Chem. 2005, 24, 199-207. [CrossRef] [PubMed]

4. Yin, T.A.; Qin, W. Applications of Nanomaterials in Potentiometric Sensors. Trends Anal. Chem. 2013, 51, 79-86. [CrossRef] 